\title{
Genetic Differentiation of Opisthorchis-Like Eggs in Northern Thailand Using Stool Specimens Under National Strategic Plan to Control Liver Fluke Infection and Cholangiocarcinoma
}

\author{
Saiwasan Buathong, ${ }^{1,2}$ Kateitsaray Phaiphilai, ${ }^{3}$ Toon Ruang-areerate, ${ }^{1}$ Naruemon Sitthichot, ${ }^{1}$ Thanyapit Thita, ${ }^{4}$ \\ Mathirut Mungthin, ${ }^{1}$ and Picha Suwannahitatorn ${ }^{1 \star}$ \\ ${ }^{1}$ Department of Parasitology, Phramongkutklao College of Medicine, Bangkok, Thailand; ${ }^{2}$ Department of Clinical Pathology, Faculty of Medicine \\ Vajira Hospital, Navamindradhiraj University, Bangkok, Thailand; ${ }^{3}$ Communicable Disease Control Sector, Chiang Mai Provincial Health Office, \\ Chiang Mai, Thailand; ${ }^{4}$ Drug Research Unit for Malaria, Faculty of Tropical Medicine, Mahidol University, Bangkok, Thailand
}

\begin{abstract}
Liver fluke infection caused by Opisthorchis viverrini is recognized as a potential risk factor for cholangiocarcinoma (CCA). The National Strategic Plan to Control Liver Fluke Infection and Cholangiocarcinoma has implemented microscopic-based stool examination screening. However, eggs of $O$. viverrini and minute intestinal flukes (MIFs) are nearly morphologically similar and could result in inaccurate O. viverrini diagnosis. Stool specimens were collected from eight districts of Chiang Mai Province in northern Thailand. Opisthorchis-like eggs were identified with the Kato-Katz technique and differentiated for O. viverrini and MIFs using molecular study by PCR and PCR-restriction fragment length polymorphism targeting the internal transcribed spacer 2 (ITS2) gene. Prevalence of Opisthorchis-like eggs was 5.9\% from a total of 9,570 specimens. From PCR assays, all liver flukes were O. viverrini and all MIFs were Haplorchis taichui. The distribution of species was $H$. taichui $(38.2 \%)$, O. viverrini $(10.5 \%)$, coinfection of $H$. taichui and O. viverrini $(37.2 \%)$, and $14.1 \%$ were negative from PCR. Totally, $H$. taichui was found in $75.4 \%$ of infections from Opisthorchis-like specimens. ITS2 nucleotide sequencing analysis showed a single variant of $O$. viverrini with no variation and two variants of $H$. taichui. This study first revealed the genetic background of Opisthorchis-like eggs in northern Thailand. Minute intestinal flukes are occasionally misdiagnosed as $O$. viverrini leading to misinterpretation and overestimation of the burden of $O$. viverrini infection. Molecular diagnosis such as PCR could effectively discriminate species of Opisthorchis-like eggs and help shape the robustness of epidemiological data to control liver fluke infection and raise awareness of other risk factors for CCA.
\end{abstract}

\section{INTRODUCTION}

Human liver fluke infection caused by Opisthorchis viverrini remains a major health problem in Thailand ${ }^{1,2}$ where prevalence is high in the northern and northeastern regions, ${ }^{3,4}$ which is associated with the consumption of uncooked freshwater fish containing infective-stage metacercariae. ${ }^{5}$ The nationwide prevalence of $O$. viverrini infection in 1980, 2000, and 2009 were $14.0 \%, 9.4 \%$, and $8.7 \%$, respectively, where the prevalence was greater than $15.0 \%$ in the northern and northeastern provinces. In some part of northeastern region, prevalence of $O$. viverrini infection was higher than $50.0 \%$.

Infection is typically asymptomatic resulting in low awareness and chronic infection leading to a lethal bile duct cancer, cholangiocarcinoma (CCA). A report from the Office of Disease Prevention and Control revealed that CCA has high mortality associated with high medical expense and poor quality of life. The prevalence and mortality are also expected to increase over time. Opisthorchis viverrini is commonly found in Thailand, whereas the other two species, Opisthorchis felineus and Clonorchis sinensis, are prevalent in Eastern Europe and China, respectively. The flukes need Bithynia snails serving as a first intermediate host and whitescale freshwater fish (cyprinoid) as second intermediate host. Humans are infected by consuming uncooked cyprinoid fish containing infective stage metacercariae. Adult flukes reside in the bile duct within the hepatobiliary system and produce eggs which when excreted through feces into freshwater body, the eggs hatch and infect snails to complete their life cycle. $^{8-10}$ Minute intestinal flukes (MIFs) share the same life cycle, including mode of infection. However, the first

*Address correspondence to Picha Suwannahitatorn, Department of Parasitology, Phramongkutklao College of Medicine, 317/5 Ratchawithi Rd., Bangkok 10400, Thailand. E-mail: picha.s@pcm.ac.th intermediate host is usually Thiarid snails. Therefore, the distribution of human liver flukes and MIFs depend on the abundance of their intermediate host in the environment. ${ }^{11-13}$ A national health survey conducted in 2015 by the Department of Disease Control reported that uncooked fish consumption was observed in populations in upper northern provinces. In some areas, the consumption was $80 \%$ in populations older than 15 years. Local dishes such as koi pla and larb pa, instantly prepared uncooked fish mixed with spicy herbs, are popular. $^{14}$

Clinical manifestations of $O$. viverrini infection are mostly asymptomatic. ${ }^{15}$ When the infection remains chronic, the symptoms could be the result of subsequent CCA including jaundice and an enlarged liver. The International Agency for Research on Cancer declared $O$. viverrini is carcinogenic to human. Opisthorchis viverrini infection and CCA were widely studied in northeastern Thailand. ${ }^{16-19}$ The carcinogenic process is initiated from excretory/secretory products from flukes and the human host immune response and promoted by chemical compounds such as nitrosamine. ${ }^{20,21}$ Incidence of CCA is approximately 100-200 cases/100,000 population in Khon Kaen Province, northeastern Thailand, whereas the incidence in the west is one to two cases $/ 100,000$ population.

In 2013, a screening program led by the Faculty of Public Health, Khon Kaen University, comprised screening and confirmation tests with patient management focusing on populations in the northeastern region where O. viverrini infection is prevalent (CCA Screening and Care Program). ${ }^{22}$ In 2015, the Ministry of Public Health and collaborating health agencies initiated the National Strategic Plan for Controlling Liver Fluke Infection and Cholangiocarcinoma emphasizing controlling O. viverrini infection and CCA screening from 2015 to 2025 and extending the screening area to national coverage, including the upper northern provinces of Thailand, that is, Chiang Rai, Chiang Mai, Phrae, Nan, Mae Hong Son, 
Lamphun, Lampang, and Phayao. Local health authority reported the prevalence and mortality rate from CCA are as high as found in the northeastern regions and higher than other regions of the country. The main strategy of the program aims to prevention and control $O$. viverrini infection to reduce subsequent CCA incidence. ${ }^{19,20,23}$ Unlike the northeastern region, data of $O$. viverrini infection as a risk factor for CCA in northern region were still limited. ${ }^{24}$

The screening test for $O$. viverrini infection is made by direct stool examination using the Kato-Katz technique and examining stool samples for $O$. viverrini eggs under a microscope. The method provides good accuracy and remains practical for local ambulatory settings with limited resources. ${ }^{25-27} \mathrm{How}-$ ever, O. viverrini eggs are almost morphologically similar to MIF eggs under a microscope and difficult to differentiate in routine practice, ${ }^{28,29}$ which could be called Opisthorchis-like eggs. Moreover, $O$. viverrini and MIFs can be distinguished by identifying adult worms, ${ }^{29,30}$ but collecting the parasite is impractical because adult liver flukes are rarely expelled from the bile duct to stool. ${ }^{8,12,31,32}$

National Strategic Plan to Control Liver Fluke Infection and Cholangiocarcinoma emphasized on targeting population from high-risk areas of CCA. ${ }^{33}$ Therefore, Opisthorchis-like eggs identified with the Kato-Katz technique were presumably diagnosed as $O$. viverrini based on previous baseline epidemiological data, which were mainly obtained from endemic northeastern region. ${ }^{20,34,35}$ However, O. viverrini were not uniformly distributed outside endemic area, and the increased prevalence in northern Thailand could be a result from misdiagnosis of MIFs due to limitation of the Kato-Katz technique. ${ }^{36}$ In northern Thailand, the studies of Opisthorchislike eggs have revealed that MIFs are found in both cyprinoid fish and residents. ${ }^{37,38}$ A previous PCR study from Chiang Mai Province, northern Thailand, revealed that Opisthorchis-like eggs obtained from stool specimen were coinfection of 0 . viverrini and Haplorchis taichui. ${ }^{39}$ Therefore, additional epidemiological data are needed to determine the prevalence of Opisthorchis-like eggs based on geographical distribution. In this study, screening tests were performed using stool examination to determine the prevalence of Opisthorchis-like eggs following the National Strategic Plan to Control Liver Fluke Infection and Cholangiocarcinoma. We assumed that Opisthorchis-like eggs may not be $O$. viverrini eggs exclusively from microscopy-based stool examination. Consequently, eggs from specimens were further tested using molecular techniques to discriminate $O$. viverrini and MIF infection. We also showed genetic information of Opisthorchis-like eggs in the designated study areas. The data will help understanding the distribution of $O$. viverrini and MIF infections within the areas under the screening program. Up-to-date data are needed for policy makers, especially when CCA could also be the result from other causes despite $O$. viverrini infection. ${ }^{40,41}$

\section{MATERIALS AND METHODS}

Ethics. The research protocol was reviewed and approved by the Ethics Committee of The Royal Thai Army Medical Department (Ref. S025h/51 and S045h/54).

Study area. The research employed a cross-sectional design using a laboratory study. Stool specimens were examined using the molecular technique from a stool bank collected from the Stool Screening Program under the National
Strategic Plan to Control Liver Fluke Infection and Cholangiocarcinoma. Study areas comprised eight districts in Chiang Mai Province, upper northern Thailand. The areas are under the supervision of the Chiang Mai Provincial Health Office.

Stool preparation. According to the screening program, the Office of Public Health in each district performed the Kato-Katz stool examination for Opisthorchis-like egg detection. Specimens presenting Opisthorchis-like eggs were collected by the Provincial Health Office to the stool bank and later sent to the laboratory at the Phramongkutklao College of Medicine. Stool specimens were then prepared for molecular study. DNA was extracted from the sediment of phosphate buffer saline (PBS) ethyl acetate stool preparation. PCR and PCR-restriction fragment length polymorphism (PCR-RFLP) were performed to discriminate opisthorchiid flukes (O. viverrini and $C$. sinensis) and heterophyid flukes using RTFluke primers ${ }^{42}$ targeting the ITS2 gene. The protocol was developed by Buathong ${ }^{28,43}$ and published elsewhere. From the protocol, MIFs detected from this study would be heterophyid flukes accordingly.

DNA extraction of Opisthorchis-like eggs. Opisthorchislike eggs, collected from PBS ethyl acetate concentration technique, were used for DNA extraction. Each positive sample of $200 \mu \mathrm{L}$ of sediment was incubated at $4^{\circ} \mathrm{C}$ for 2 days, ${ }^{44}$ added with $1.4 \mathrm{~mL}$ ATL tissue lysis buffer (Qiagen, Hilden, Germany), and mixed continuously for 1 minute or until the stool samples were thoroughly homogenized. The suspension was subjected for six cycles of freezing in liquid nitrogen followed by thawing at $98-100^{\circ} \mathrm{C}$. Subsequently, the suspension was heated at $70^{\circ} \mathrm{C}$ for 20 minutes before continuously mixing and centrifuging at $20,000 \mathrm{~g}$ for 1 minute to solidify sediment fecal pellets. The amount of $1.2 \mathrm{~mL}$ supernatant was transferred to a new 2-mL microcentrifuge tube. The DNA was extracted from the supernatant using QIAmp DNA Stool Mini Kit (Qiagen) according to the manufacturer's protocol by modifying the standard protocol by occasional vortex using a thermomixer applied every 5 minutes for 0.5 hours during incubation at $70^{\circ} \mathrm{C}$ to improve DNA quality. ${ }^{45}$ At the final step, DNA was eluted with $50 \mu \mathrm{L}$ of elution buffer.

PCR assay for amplifying of Opisthorchis-like eggs in stool samples. The positive samples of Opisthorchis-like eggs were subjected to triplicate PCR amplification. Two primer sets, ITS2 ${ }^{46}$ and RTFluke, ${ }^{42}$ designed for ITS2 of opisthorchiid and heterophyid flukes, were used in this study. All positive samples were first validated using ITS2 primer, and negative samples of ITS2 primer were subjected to RTFluke PCR assay to confirm the true-negative results of PCR amplification. PCR amplifications were performed in a final volume of $50 \mu \mathrm{L}$, consisting of DNA template, 10 pmole of each primer, $200 \mu \mathrm{M}$ dNTP, $2 \mathrm{mM}$ of $\mathrm{MgCl}_{2}, 1 \times$ buffer PCR, and 1 unit of Taq polymerase $(5 \mathrm{U} / \mu \mathrm{L})$ (Promega, Madison, $\mathrm{WI})$. The PCR products were amplified in the Mastercycle ${ }^{\circledR}$ Personal Cycler (Bio-Rad, Hercules, CA). For the PCR assay of ITS2 primer, the DNA samples were initially denatured at $94^{\circ} \mathrm{C}$ for 5 minutes followed by amplification of 40 cycles consisting of desaturating at $94^{\circ} \mathrm{C}$ for 1 minute, annealing at $60^{\circ} \mathrm{C}$ for 30 seconds, and elongating at $72^{\circ} \mathrm{C}$ for 2 minutes for ITS2 primer. The PCR products of O. viverrini, C. sinensis, Haplorchis pumilio, and $H$. taichui comprised $380,381,380$, and 530 bp, respectively.

RTFluke consisted of an initial stage of denaturation at $94^{\circ} \mathrm{C}$ for 15 minutes, annealing temperature at $60^{\circ} \mathrm{C}$ for 1 minute, 
extension step at $72^{\circ} \mathrm{C}$ for 2 minutes followed by 35 cycles of $94^{\circ} \mathrm{C}$ for 30 seconds, $60^{\circ} \mathrm{C}$ for 30 seconds, $72^{\circ} \mathrm{C}$ for $30 \mathrm{sec}-$ onds, a final extension at $72^{\circ} \mathrm{C}$ for 7 minutes, and a holding temperature of $12^{\circ} \mathrm{C}$ to complete amplifications. The amplicons of $O$. viverrini, $C$. sinensis, and $H$. taichui were 375,381 , and 526 bp, respectively. ${ }^{42}$

Fragment length polymorphism methods for discriminating eggs of $\boldsymbol{O}$. viverrini, $\boldsymbol{C}$. sinensis, and MIFs. The PCR products of $O$. viverrini, $C$. sinensis, and $H$. pumilio showed the same size in agarose gel. ${ }^{46}$ Therefore, PCR-RFLP was performed to discriminate eggs of $O$. viverrini and $C$. sinensis using a restriction enzyme, Faul (New England Biolabs, Ipswich, MA). ${ }^{28}$ PCR products were digested with 2 units of Faul in a total volume of $20 \mu \mathrm{L}$ at $55^{\circ} \mathrm{C}$ for $6-8$ hours. Digesting with Faul restriction enzyme, PCR-RFLP analysis was used to discriminate $O$. viverrini from $C$. sinensis, which generated the fragments of $129 \mathrm{bp}$ and $247 \mathrm{bp}$ for O. viverrini but produced undigested amplicon for $C$. sinensis and $H$. pumilio. ${ }^{28}$

Agarose gel electrophoresis and DNA sequencing. The PCR products were detected in $2 \%$ agarose gel in $1 \times$ Tris/ borate/EDTA (TBE) buffer. For DNA staining, $10 \mathrm{~mL}$ of agarose gel was mixed with $0.3 \mu \mathrm{L}$ SYBR $^{\circledR}$ safe DNA Gel Stain (Invitrogen, Waltham, MA). A 100-bp DNA ladder (Vivantis Technologies, Selangor, Malaysia) was used as a marker to estimate the sizes of PCR products. The PCR products were electrophoresed at $100 \mathrm{~V}$ at room temperature for 40 minutes. Finally, the agarose gel was visualized by molecular image ${ }^{\circledR}$ Gel Doc ${ }^{\mathrm{TM}} \mathrm{XR}+$ Imaging System (Bio-Rad). The PCR products were purified before DNA sequencing using QIAquick Gel Extraction Kit (Qiagen) according to the manufacturer's protocol. The randomly selected PCR products of Opisthorchislike eggs were sent to U2Bio Co., Ltd. (Songpa-gu, South Korea) for DNA sequencing.

Data management and analysis. Data entry and analysis were conducted using STATA ${ }^{\circledR}$ for Windows, Version 14 (StataCorp, College Station, TX). Prevalence of Opisthorchislike eggs, $O$. viverrini, and small intestinal fluke infections were reported as percentage.

DNA analysis and phylogenetic tree of Opisthorchis-like egg. The randomly selected PCR products of $380 \mathrm{bp}$ and $530 \mathrm{bp}$ were sent to the First BASE laboratories (First BASE Laboratories, The Gemini, Singapore) for DNA sequencing.
The sequences were subjected to an NCBI BLAST search to identify species. The DNA sequences were aligned using the BioEdit Program, version 7.0.9, and MEGA5, version 5.05 (http://www.megasoftware.net/), to determine the similarity by generating the phylogenetic relationships of Opisthorchiidae and Heterophyidae families. For this, Metagonimus guianensis and Centrocestus formosanus were chosen as an out-group for Opisthorchiidae, whereas $C$. sinensis was chosen for Heterophyidae. RAxML analysis was used to construct the ITS2 trees of both Opisthorchiidae and Heterophyidae based on RAxML, version 7.4.2, with a GTR matrix (GTR + $\Gamma$ model) ${ }^{47}$ using raxmIGUI, version $1 .{ }^{48}$ The clade stability of the tree topology was evaluated using 1,000 replicates of RAxML bootstrap values.

Accession numbers. All data are available through the GenBank database with the following accession numbers. Haplorchis taichui: GQ176380.1, AB517576.1, MH991969.1, MK790157.1, KP165440.1, KP165440.1, MH991968.1, MH991968.1, MT006044, MT006045, МT006046, MT006047, MT006048, МT006049, МT006050, МT006051, МT006052, MT006053, MT006054, and MT006055. Metagonimus guianensis: KX387524.1. Centrocestus formosanus: KY075665.1. Opisthorchis viverrini: KT726408.1, HQ328548.1, AY584735.1, MK886660.2, MK886661.2, MK886662.2, MK886663.2, MT002729, МT002730, МТ002731, МТ002732, МТ002733, MT002734, and MT002735. Opisthorchis labotus: HQ328545.1. Opisthorchis parageminus: KX258657. C. sinensis: EF688144.1.

\section{RESULTS}

In 2019, a total 9,570 stool specimens were collected. The prevalence of Opisthorchis-like eggs was 5.9\% (563/9,570). Then 304 samples (54.0\%) were randomly selected from 563 specimens with Opisthorchis-like eggs for molecular study.

Molecular study. PCR assay using ITS2 plus RTFLuke primers was $85.9 \%(261 / 304)$ positive in specimens with Opisthorchis-like eggs from the Kato-Katz stool examination. All liver flukes detected were O. viverrini, and all MIFs detected by PCR were $H$. taichui, as shown in Figure 1.

From Table 1, PCR-RFLP shows that 48.7\% (148/304) were single infection and $37.2 \%(113 / 304)$ were coinfection. Combining single and coinfection, $75 \%$ of positive results included

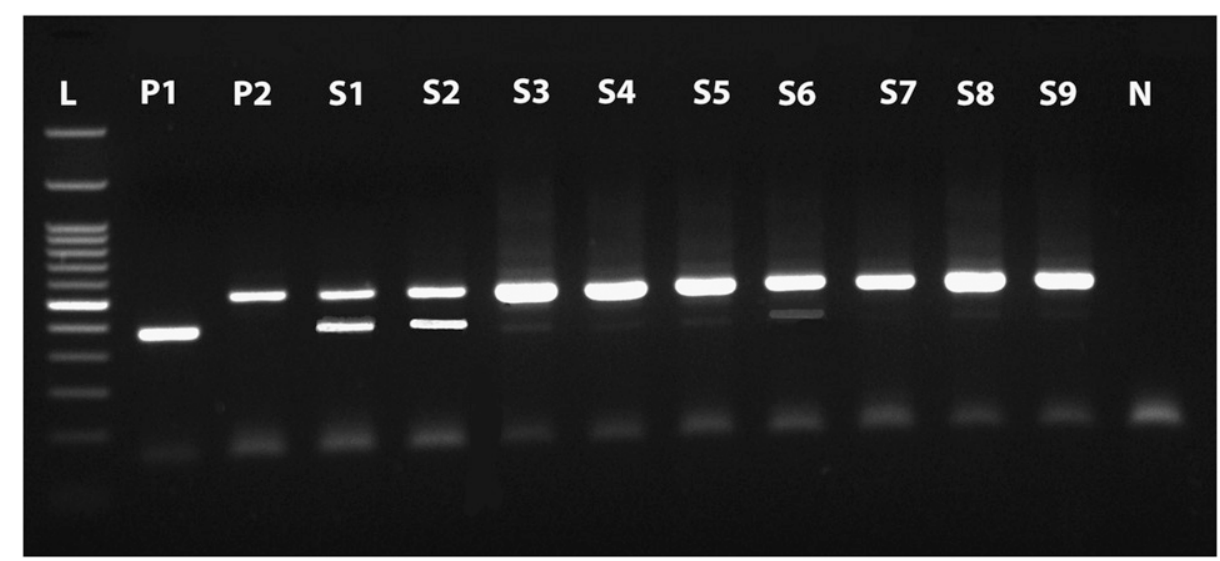

FIGURE 1. PCR products with Opisthorchis-like eggs using ITS2 primer. P1 was Opisthorchis viverrini positive, P2 was Haplorchis taichui positive, and $\mathrm{N}$ was negative. S1 to $\mathrm{S} 9$ samples were tested showing single and coinfection, accordingly. Lanes $\mathrm{S} 1, \mathrm{~S} 2$, and $\mathrm{S} 6$ were coinfection of $O$. viverrini and $H$. taichui. Lanes S3 to S5 and S7 to S9 were $H$. taichui. 
TABLE 1

Proportion of $O$. viverrini and MIF infection detected by PCR-RFLP

\begin{tabular}{lrr}
\hline & Total specimen $(n=304)$ & Excluded for negative PCR $(n=261)$ \\
\cline { 2 - 3 } \multicolumn{1}{c}{ PCR-RFLP result } & $n(\%)$ & $n(\%)$ \\
\hline Negative for PCR & $43(14.1)$ & - \\
H. taichui & $116(38.2)$ & $116(44.4)$ \\
O. viverrini & $32(10.5)$ & $32(12.3)$ \\
Coinfection of $H$. taichui and O. viverrini & $113(37.2)$ & $113(43.3)$ \\
\hline PCR-RFLP = PCR-restriction fragment length polymorphism; H. taichui = Haplorchis taichui; O. viverrini = Opisthorchis viverrini. &
\end{tabular}

$H$. taichui and $47.7 \%$ included O. viverrini infection. When excluded for negative results, highest proportion of infection was $H$. taichui (44.4\%) followed by coinfection (43.3\%). Single O. viverrini infection was $12.3 \%$ in positive results.

From Table 2, the highest numbers of Opisthorchis-like specimens were collected from Doi Tao/Chom Thong districts followed by Mae Taeng District. The highest proportion of H. taichui and O. viverrini infection was $56.4 \%$ in Mae Taeng District and $27.3 \%$ in Doi Tao/Chom Thong districts, respectively. Coinfection was highest in Samoeng District (66.7\%). Chai Prakan District had the highest proportion of negative PCR results (30.8\%). Among 304 specimens from eight districts, four specimens were from unknown areas. However, they were collected from within the studied districts for which three specimens $(75 \%)$ were $H$. taichui and one specimen (25\%) indicated coinfection.

DNA sequencing of Opisthorchis-like eggs. Seven randomly selected $O$. viverrini ITS2 sequences from eight districts in Chiang Mai were analyzed and subjected to BLAST NCBI. The result of BLAST showed that ITS2 sequences of $O$. viverrini obtained from this study were genetically identical to O. viverrini, accession number MK886660.2, MK886663.2, MK886662.2, and MK886661.2, with 100\% identity. DNA sequence alignment presented single variant and no genetic variation of ITS2 sequences. Moreover, 12 sequences of $H$. taichui PCR products were genetically identical to $H$. taichui, accession number MK790157.1, GQ176380.1, MH991969.1, and $A B 517576.1$, isolate with $100 \%$ identity. In addition, DNA sequencing alignment of 12 sequences of $H$. taichui showed two variants. Seven sequences of $O$. viverrini and 12 sequences of $H$. taichui obtained from this study were submitted to GenBank to obtain accession number.

Phylogenetic tree analysis. A phylogenetic tree of MIFs based on 492 bp of the ITS2 gene was constructed using 12 $H$. taichui DNA sequences isolated in this study and eight referent $H$. taichui (Figure 2) sequences retrieved from GenBank. Metagonimus guianensis and C. formosanus were used as an out-group. The tree topologies of MIFs revealed that $H$. taichui formed paraphyletic relationships with other two species of MIFs (bootstrap value $=100 \%$ ). Isolates of $H$. taichui $(n=12)$ (MT006045-MT006054) collected in this study were clustered within the $H$. taichui group (bootstrap value $=100 \%$ ) forming strictly monophyletic relationships with others from Thailand (MH991969.1 and AB517576.1) and Vietnam (MK790157.1 and GQ176380.1) representing shared ancestor. However, two referent isolates (HM004155.1 and MH991968.1) were separated from the others. Regarding strong support of the bootstrap value (bootstrap value $=96 \%$ ), the exchanges between branches were less likely to occur, representing shared ancestor in $H$. taichui isolates of this study.

The ITS2 tree of $O$. viverrini based on $377 \mathrm{bp}$, constructed using seven isolate sequences in this study and nine reference Opisthorchis genera sequences with $C$. sinensis as an out group, demonstrated paraphyletic relationships among O. viverrini with bootstrap value less than $50 \%$ causing uncertain diversity in the $O$. viverrini group (Figure 3 ). Interestingly, the clade of our seven isolates (MT002729-MT002735) strictly formed a monophyletic group with that of a related report from eastern Thailand (MK886660.2, MK886661.2, MK886662.2, and MK886663.2) (bootstrap value $=78 \%$ ) and clearly separated from five reference isolates (HQ328545, HQ328548, KT726408, AY584735, and KX258657).

\section{DISCUSSION}

This is the first report to discriminate O. viverrini and MIF infection from Opisthorchis-like eggs using PCR assays in northern Thailand. According to the National Strategic Plan for Controlling Liver Fluke Infection and CCA, the program emphasizes controlling $O$. viverrini infection, and reports show that the incidence of CCA is high in upper northern provinces where the practice of consuming uncooked fish is popular. However, the program primarily examined stool samples to

TABLE 2

Distribution of $O$. viverrini and minute intestinal fluke infection as detected by district

\begin{tabular}{|c|c|c|c|c|c|c|}
\hline & & & H. taichui & O. viverrini & $\begin{array}{l}\text { Coinfection of } H \text {. taichui } \\
\text { and O. viverrini }\end{array}$ & $\begin{array}{l}\text { Negative } \\
\text { for PCR }\end{array}$ \\
\hline District & $\begin{array}{l}\text { Prevalence of Upisthorchis- } \\
\text { like eggs }(\%)\end{array}$ & $\begin{array}{l}\text { Number of UpIsthorchis- } \\
\text { like eggs }\end{array}$ & \multicolumn{4}{|c|}{$n(\%)$} \\
\hline Doi Tao/Chom Thong & 8.1 & 99 & $12(12.1)$ & $27(27.3)$ & $54(54.5)$ & $6(6.1)$ \\
\hline Mae Taeng & 13.3 & 94 & $53(56.4)$ & $2(2.1)$ & $27(28.7)$ & $12(12.8)$ \\
\hline Chiang Dao & 6.6 & 67 & 31 (46.3) & 0 & 18 (26.9) & $18(26.9)$ \\
\hline Fang & 2.0 & 16 & $7(43.8)$ & $3(18.8)$ & $5(31.3)$ & $1(6.3)$ \\
\hline Chai Prakan & 2.8 & 13 & $7(53.8)$ & 0 & $2(15.4)$ & $4(30.8)$ \\
\hline Samoeng & 2.7 & 9 & $3(33.3)$ & 0 & $6(66.7)$ & 0 \\
\hline Mae Ai & 1.5 & 2 & 0 & 0 & 0 & $2(100.0)$ \\
\hline
\end{tabular}

$n=300$, excluding four samples from unknown areas within eight studied districts. 


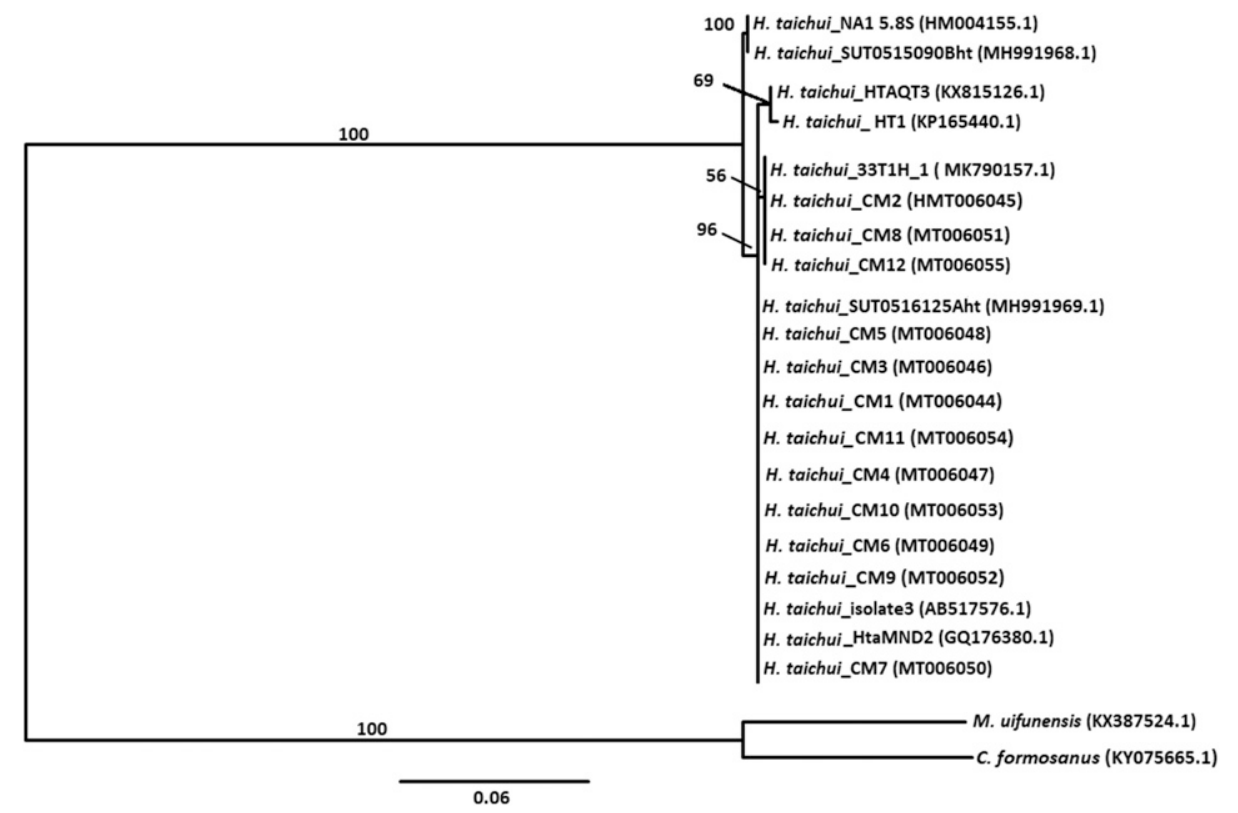

FIGURE 2. Randomized Axelerated Maximum Likelihood tree based on the ITS2 sequences of minute intestinal flukes. The alignment of 429 nucleotide sequences without gaps and 12 isolates from eight villages (isolates CM1-CM12) were analyzed. Haplorchis taichui isolates NA1 $5.8 \mathrm{~S}$, SUT0515090Bht, HTAQT3, HT1, 33T1H_1, SUT0516125Aht, isolate3, and HtaMND2 were used as the reference isolates. The percentages of 1,000 replications (bootstraps) of more than $50 \%$ are shown at the nodes.

determine O. viverrini infection, which could not effectively discriminate $O$. viverrini and MIF infection from specimens. Distribution data of Opisthorchis-like eggs could play an important role for program planning. Some areas with high incidences of CCA might not have high prevalence of $O$. viverrini infection.

Diagnosis of $O$. viverrini and MIF infection is practically made by microscopy-based stool examination. Direct simple smear can identify various parasitic infections, including helminth eggs and protozoa. Preparation technique to increase fecal material concentration such as the Kato-Katz thick smear or formalin-ethyl concentration technique (FECT) could increase sensitivity of the test. ${ }^{26,27,29,49}$ However, diagnosis depends on identifying eggs under light microscope. Studies of Opisthorchis-like eggs conducted by Radomyos et al. ${ }^{37,50}$ and Wijit et al. ${ }^{32}$ in upper northern provinces revealed that most adult flukes collected from participants were MIFs, which is not a risk factor for CCA. In central and northeastern Thailand, Opisthorchis-like eggs were mostly identified as 0 . viverrini infection ${ }^{5,45}$ and are significantly related to CCA occurrence. ${ }^{18,40}$ Several works used PCR to study rDNA ITS1 and the ITS2 region to differentiate $O$. viverrini and MIFs. ${ }^{46,51}$ PCR showed better performance than concentration techniques such as FECT, especially in low infection intensity areas. Many studies of Opisthorchis-like eggs in northern provinces of Thailand revealed MIFs, particularly $H$. taichui was a dominant fish-borne trematode in these regions. From 2015 to 16 , one study in upper north provinces using purgative magnesium sulfate revealed $70 \%$ of Opisthorchis-like eggs were positive for $H$. taichui, but $O$. viverrini was undetected by $\mathrm{PCR}^{32}$ The PCR assay-based rDNA ITS2 region was used to detect Opisthorchis-like eggs from stool specimens in this study. ITS2 primer was mainly applied to detect Opisthorchislike eggs with a high sensitivity of $95.2 \%$ to detect, whereas
RTFluke primer indicated only $71.0 \% .{ }^{42}$ ITS2 primer revealed a higher proportion of infection of $H$. taichui and coinfection of $H$. taichui and $O$. viverrini than single $O$. viverrini infection.

This study first showed a high coinfection of $O$. viverrini and $H$. taichui of $37.2 \%$ using PCR assay. Only $H$. taichui and $O$. viverrini were found in this study, but $H$. pumilio and C. sinensis were not observed, suggesting the distribution pattern of fish-borne trematode in northern Thailand. Using two primer sets could increase the sensitivity of detecting Opisthorchis-like eggs in stool specimens. RTFluke primer could amplify Opisthorchis-like eggs in 9.5\% (29/304) of negative samples from ITS2 primers. DNA extraction might

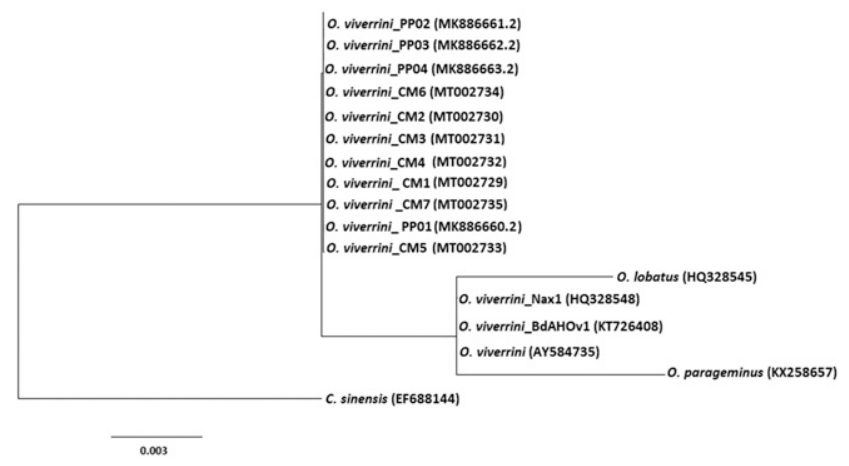

FIGURE 3. Randomized Axelerated Maximum Likelihood tree based on the ITS2 sequences of liver flukes. The alignment of 377 nucleotide sequences without gaps and seven isolates from eight districts (isolate; CM1-CM17) were analyzed. Opisthorchis viverrini isolates PP01, PP02, PP03, PP04, Nax1, BdAHOv1, and AY584735.1; Opisthorchis lobatus; and $O$. parageminus were used as the reference isolates. The percentages of 1,000 replications (bootstraps) of more than $50 \%$ are shown at the nodes. 
have been affected by inadequate amounts of stool specimens. Therefore, the quality of DNA extraction, sensitivity and specificity of primers, and optimal PCR conditions are crucial to detect and discriminate Opisthorchis-like eggs in stool specimens. However, this work emphasized on molecular study from the collected specimen. Demographic, risk behavior, and spatial data could be incorporated in further studies to determine the risk for acquiring $O$. viverrini and MIF infection.

DNA sequencing analysis of ITS2 sequences of $O$. viverrini showed only single variants without variation. Moreover, ITS2 sequences of $O$. viverrini in this study were genetically identical to submitted sequences in the GenBank database and had no variation of rDNA in the ITS2 region. Therefore, other genetic markers, that is, cytochrome $c$ oxidase subunit I and reduced nicotinamide adenine dinucleotide dehydrogenase subunit 1 should be used to study the genetic population of O. viverrini in northern Thailand. ${ }^{28,52,53}$ Minute intestinal flukes in this study were predominantly identified as $\mathrm{H}$. taichui and clustered into two variant groups. Moreover, $H$. taichui obtained from this study was genetically similar to $H$. taichui found in Vietnam (accession number MK790157.1 and GQ176380.1) and Thailand (accession number MH991969.1 and AB517576.1) with $100 \%$ identity. Opisthorchis viverrini obtained from this study was genetically similar to $O$. viverrini isolated from eastern Thailand with $100 \%$ identity. ${ }^{45}$

Epidemiological data of $O$. viverrini and MIF infection and biological diversity will be valuable for public health purposes and helpful in shaping healthcare policy. Opisthorchis-like eggs, diagnosed from microscopic-based examination, could be either $O$. viverrini or MIF eggs. In some area with high prevalence of MIF infections, CCA might be influenced by other factors in addition to parasitic infections which could potentially affect the strategic plans to control $O$. viverrini infection to reduce CCA. More broadly, $O$. viverrini is not the only carcinogenic factor of CCA; other examples could similarly benefit from proactively bridging infectious and noninfectious factors. Using molecular studies could help shape the robustness of epidemiological data to control liver fluke infection and raise awareness for other risk factors for CCA despite O. viverrini infection.

Received March 31, 2020. Accepted for publication May 20, 2020.

Published online June 22, 2020.

Acknowledgments: We gratefully thank members of staff from the Communicable Disease Control Sector, Chiang Mai Provincial Health Office, Thailand. We acknowledge the cooperation from local authorities, local health volunteers, and all participants from the districts of Doi Tao, Chom Thong, Mae Taeng, Chiang Dao, Fang, Chai Prakan, Samoeng, and Mae Ai, Chiang Mai Province, Thailand.

Financial support: This research did not receive any specific grant from funding agencies in the public, commercial, or not-for-profit sectors.

Authors' addresses: Saiwasan Buathong, Department of Parasitology, Phramongkutklao College of Medicine, Bangkok, Thailand, and Department of Clinical Pathology, Faculty of Medicine Vajira Hospital, Navamindradhiraj University, Bangkok, Thailand, E-mails: tiktok_ bua@hotmail.com and saiwasan@nmu.ac.th. Kateitsaray Phaiphilai, Communicable Disease Control Sector, Chiang Mai Provincial Health Office, Chiang Mai, Thailand, E-mail: hootho@gmail.com. Toon Ruang-areerate, Naruemon Sitthichot, Mathirut Mungthin, and Picha Suwannahitatorn, Department of Parasitology, Phramongkutklao College of Medicine, Bangkok, Thailand, E-mails: youangtr@yahoo.com, sitthichot.n@gmail.com, mathirut@hotmail.com, and picha.s@ pcm.ac.th. Thanyapit Thita, Drug Research Unit for Malaria, Faculty of Tropical Medicine, Mahidol University, Bangkok, Thailand, E-mail: thithanyapit@gmail.com.

\section{REFERENCES}

1. Kaewpitoon N, Kaewpitoon SJ, Pengsaa P, 2008. Opisthorchiasis in Thailand: review and current status. World J Gastroenterol 14: 2297-2302.

2. Upatham ES, Viyanant V, 2003. Opisthorchis viverrini and opisthorchiasis: a historical review and future perspective. Acta Trop 88: 171-176.

3. Suwannahitatorn $P$, Klomjit $S$, Naaglor T, Taamasri $P$, Rangsin $R$, Leelayoova S, Mungthin M, 2013. A follow-up study of Opisthorchis viverrini infection after the implementation of control program in a rural community, central Thailand. Parasit Vectors 6: 188.

4. Rangsin R, Mungthin $M$, Taamasri $P$, Mongklon $S$, Aimpun $P$, Naaglor T, Leelayoova S, 2009. Incidence and risk factors of Opisthorchis viverrini infections in a rural community in Thailand. Am J Trop Med Hyg 81: 152-155.

5. Sithithaworn P, Andrews RH, Nguyen VD, Wongsaroj T, Sinuon M, Odermatt P, Nawa Y, Liang S, Brindley PJ, Sripa B, 2012. The current status of opisthorchiasis and clonorchiasis in the Mekong basin. Parasitol Int 61: 10-16.

6. Brockelman WY et al., 2012. Epidemiology of Opisthorchis viverrini in a rural district of southern Lao PDR. Trans $R$ Soc Trop Med Hyg 81: 327-335.

7. Sithithaworn $P$, Andrews $R H$, Nguyen VDe, Wongsaroj $T$, Sinuon M, Odermatt P, Nawa Y, Liang S, Brindley PJ, Sripa B, 2012. The current status of opisthorchiasis and clonorchiasis in the Mekong basin. Parasitol Int 61: 10-16.

8. Harinasuta C, Harinasuta T, 1984. Opisthorchis viverrini: life cycle, intermediate hosts, transmission to man and geographical distribution in Thailand. Arzneimittelforschung 34: 1164-1167.

9. Petney T, Sithithaworn P, Andrews R, Kiatsopit N, Tesana S, Grundy-Warr C, Ziegler A, 2012. The ecology of the Bithynia first intermediate hosts of Opisthorchis viverrini. Parasitol Int 61: 38-45.

10. Touch S, Komalamisra C, Radomyos P, Waikagul J, 2009. Discovery of Opisthorchis viverrini metacercariae in freshwater fish in southern Cambodia. Acta Trop 111: 108-113.

11. Chai JY, Darwin Murrell K, Lymbery AJ, 2005. Fish-borne parasitic zoonoses: status and issues. Int J Parasitol 35: 1233-1254.

12. Keiser J, Utzinger J, 2009. Food-borne trematodiases. Clin Microbiol Rev 22: 466-483.

13. Rim HJ, Sohn WM, Yong TS, Eom KS, Chai JY, Min DY, Lee SH, Hoang EH, Phommasack B, Insisiengmay S, 2013. Fishborne trematode metacercariae in Luang Prabang, Khammouane, and Saravane province, Lao PDR. Korean J Parasitol 51: 107-114.

14. Prasongwatana J, Laummaunwai P, Boonmars T, Pinlaor S, 2013. Viable metacercariae of Opisthorchis viverrini in northeastern Thai cyprinid fish dishes-as part of a rational program for control of $O$. viverrini-associated cholangiocarcinoma. Parasitol Res 112: 1323-1327.

15. Mairiang $E$, Mairiang $P, 2003$. Clinical manifestation of opisthorchiasis and treatment. Acta Trop 88: 221-227.

16. Kaewpitoon N, Kaewpitoon SJ, Pengsaa P, Sripa B, 2008. Opisthorchis viverrini: the carcinogenic human liver fluke. World $J$ Gastroenterol 14: 666-674.

17. Parkin DM, Ohshima H, Srivatanakul P, Vatanasapt V, 1993. Cholangiocarcinoma: epidemiology, mechanisms of carcinogenesis and prevention. Cancer Epidemiol Biomarkers Prev 2: 537-544.

18. Poomphakwaen K, Promthet S, Kamsa-Ard S, Vatanasapt P, Chaveepojnkamjorn W, Klaewkla J, Sujirarat D, Pichainarong $\mathrm{N}, 2009$. Risk factors for cholangiocarcinoma in Khon Kaen, Thailand: a nested case-control study. Asian Pac J Cancer Prev 10: 251-258.

19. Smout MJ, Sripa B, Laha T, Mulvenna J, Gasser RB, Young ND, Bethony JM, Brindley PJ, Loukas A, 2011. Infection with the carcinogenic human liver fluke, Opisthorchis viverrini. Mol Biosyst 7: 1367-1375. 
20. Songserm N, Promthet S, Sithithaworn P, Pientong C, Ekalaksananan T, Chopjitt P, Parkin DM, 2012. Risk factors for cholangiocarcinoma in high-risk area of Thailand: role of lifestyle, diet and methylenetetrahydrofolate reductase polymorphisms. Cancer Epidemiol 36: e89-e94.

21. Migasena $P, 1982$. Liver flukes relationship to dietary habits and development programs in Thailand. Advers Eff Foods 1982: 307-311.

22. Chamadol N, Khuntikeo N, Thinkhamrop B, Thinkhamrop K, Suwannatrai AT, Kelly M, Promthet S, 2019. Association between periductal fibrosis and bile duct dilatation among a population at high risk of cholangiocarcinoma: a crosssectional study of cholangiocarcinoma screening in northeast Thailand. BMJ Open 9: e023217.

23. Sripa B et al., 2007. Liver fluke induces cholangiocarcinoma. PLoS Med 4: e201.

24. Steele JA, Richter $\mathrm{CH}$, Echaubard $P$, Saenna $P$, Stout $V$, Sithithaworn P, WilcoxBA, 2018. Thinking beyond Opisthorchis viverrini for risk of cholangiocarcinoma in the lower Mekong region: a systematic review and meta-analysis. Infect Dis Poverty 7: 44.

25. Bergquist R, Johansen MV, Utzinger J, 2009. Diagnostic dilemmas in helminthology: what tools to use and when? Trends Parasitol 25: 151-156.

26. Tungtrongchitr A, Chiworaporn $C$, Praewanich R, Radomyos $P$, Boitano JJ, 2007. The potential usefulness of the modified Kato thick smear technique in the detection of intestinal sarcocystosis during field surveys. Southeast Asian J Trop Med Public Health 38: 232-238.

27. Qian MB, Yap P, Yang YC, Liang H, Jiang ZH, Li W, Utzinger J, Zhou XN, Keiser J, 2013. Accuracy of the Kato-Katz method and formalin-ether concentration technique for the diagnosis of Clonorchis sinensis, and implication for assessing drug efficacy. Parasit Vectors 6: 314.

28. Buathong $S$, Leelayoova $S$, Mungthin M, Ruang-Areerate $T$, Naaglor T, Suwannahitatorn P, Piyaraj P, Taamasri P, Tan-ariya $P, 2017$. Molecular discrimination of Opisthorchis-like eggs from residents in a rural community of central Thailand. PLoS Negl Trop Dis 11: e0006030.

29. Tesana S, Srisawangwonk T, Kaewkes $S$, Sithithaworn $P$, Kanla $P$, Arunyanart C, 1991. Eggshell morphology of the small eggs of human trematodes in Thailand. Southeast Asian J Trop Med Public Health 22: 631-636.

30. Kaewkes S, Elkins DB, Sithithaworn P, Haswell-Elkins MR, 1991. Comparative studies on the morphology of the eggs of Opisthorchis viverrini and lecithodendriid trematodes. Southeast Asian J Trop Med Public Health 22: 623-630.

31. Furst T, Duthaler U, Sripa B, Utzinger J, Keiser J, 2012. Trematode infections: liver and lung flukes. Infect Dis Clin North Am 26: 399-419.

32. Wijit A, Morakote N, Klinchid J, 2013. High prevalence of haplorchiasis in Nan and Lampang provinces, Thailand, proven by adult worm recovery from suspected opisthorchiasis cases. Korean J Parasitol 51: 767-769.

33. Khuntikeo $\mathrm{N}$ et al., 2015. Cohort profile: cholangiocarcinoma screening and care program (CASCAP). BMC Cancer 15: 459.

34. Sripa B, Bethony JM, Sithithaworn P, Kaewkes S, Mairiang E, Loukas A, Mulvenna J, Laha T, Hotez PJ, Brindley PJ, 2011. Opisthorchiasis and Opisthorchis-associated cholangiocarcinoma in Thailand and Laos. Acta Trop 120 (Suppl 1): S158-S168.

35. Sriamporn S, Pisani P, Pipitgool V, Suwanrungruang K, Kamsaard S, Parkin DM, 2004. Prevalence of Opisthorchis viverrini infection and incidence of cholangiocarcinoma in Khon Kaen, northeast Thailand. Trop Med Int Health 9: 588-594.

36. Sithithaworn P, Haswell-Elkins M, 2003. Epidemiology of Opisthorchis viverrini. Acta Trop 88: 187-194.

37. Radomyos $B$, Wongsaroj $T$, Wilairatana $P$, Radomyos $P$, Praevanich $\mathrm{R}$, Meesomboon V, Jongsuksuntikul P, 1998. Opisthorchiasis and intestinal fluke infections in northern Thailand. Southeast Asian J Trop Med Public Health 29: 123-127.

38. Krailas D, Veeravechsukij N, Chuanprasit C, Boonmekam D, Namchote S, 2016. Prevalence of fish-borne trematodes of the family Heterophyidae at Pasak Cholasid Reservoir, Thailand. Acta Trop 156: 79-86.

39. Wongsawad C, Phalee A, Noikong W, Chuboon S, Nithikathkul C, 2012. Co-infection with Opisthorchis viverrini and Haplorchis taichui detected by human fecal examination in Chomtong district, Chiang Mai province, Thailand. Parasitol Int 61: 56-59.

40. Kamsa-ard S, Kamsa-ard S, Luvira V, Suwanrungruang K, Vatanasapt P, Wiangnon S, 2018. Risk factors for cholangiocarcinoma in Thailand: a systematic review and metaanalysis. Asian Pac J Cancer Prev 19: 605-614.

41. Insamran W, Sangrajrang S, 2020. National cancer control program of Thailand. Asian Pac J Cancer Prev 21: 577-582.

42. Traub RJ, Macaranas J, Mungthin M, Leelayoova S, Cribb T, Murrell KD, Thompson RC, 2009. A new PCR-based approach indicates the range of Clonorchis sinensis now extends to central Thailand. PLoS Negl Trop Dis 3: e367.

43. Buathong $S$, Leelayoova $S$, Mungthin $M$, Naaglor T, Taamasri $P$, Suwannahitatorn P, Tan-Ariya P, 2015. Development and evaluation of PCR methods based on cytochrome $c$ oxidase subunit one (cox1) and NADH dehydrogenase subunit one gene (nad1) to detect Opisthorchis viverrini in human fecal samples. Parasitol Res 114: 3547-3549.

44. Buathong S, Mungthin M, Tan-ariya P, Naaglor T, Taamasri $P$, Suwannahitatorn P, Leelayoova S, 2010. PBS incubation, a simple technique to release miracidia of Opisthorchis-like eggs for DNA extraction. Exp Parasitol 124: 357-359.

45. Boondit J, Suwannahitatorn P, Siripattanapipong S, Leelayoova $S$, Mungthin M, Tan-Ariya P, Piyaraj P, Naaglor T, RuangAreerate T, 2020. An epidemiological survey of Opisthorchis viverrini infection in a lightly infected community, eastern Thailand. Am J Trop Med Hyg 102: 838-843.

46. Sato M, Thaenkham U, Dekumyoy P, Waikagul J, 2009. Discrimination of $O$. viverrini, $C$. sinensis, $H$. pumilio and $H$. taichui using nuclear DNA-based PCR targeting ribosomal DNA ITS regions. Acta Trop 109: 81-83.

47. Stamatakis A, 2006. RAxML-VI-HPC: maximum likelihood-based phylogenetic analyses with thousands of taxa and mixed models. Bioinformatics 22: 2688-2690.

48. Silvestro D, Michalak I, 2012. raxmIGUI: a graphical front-end for RAxML. Org Divers Evol 12: 335-337.

49. Glinz D, Silue KD, Knopp S, Lohourignon LK, Yao KP, Steinmann P, Rinaldi L, Cringoli G, N'Goran EK, Utzinger J, 2010. Comparing diagnostic accuracy of Kato-Katz, Koga agar plate, ether-concentration, and FLOTAC for Schistosoma mansoni and soil-transmitted helminths. PLoS Negl Trop Dis 4: e754.

50. Radomyos P, Radomyos B, Tungtrongchitr A, 1994. Multiinfection with helminths in adults from northeast Thailand as determined by post-treatment fecal examination of adult worms. Trop Med Parasitol 45: 133-135.

51. Sato M et al., 2010. Copro-DNA diagnosis of Opisthorchis viverrini and Haplorchis taichui infection in an endemic area of Lao PDR. Southeast Asian J Trop Med Public Health 41: 28-35.

52. Saijuntha W, Sithithaworn $P$, Wongkham S, Laha T, Chilton NB, Petney TN, Barton M, Andrews RH, 2008. Mitochondrial DNA sequence variation among geographical isolates of Opisthorchis viverrini in Thailand and Lao PDR, and phylogenetic relationships with other trematodes. Parasitology 135: 1479-1486.

53. Thaenkham $U$, Nuamtanong $S$, Sa-nguankiat $S$, Yoonuan $T$, Touch S, Manivong K, Vonghachack Y, Sato M, Waikagul J, 2010. Monophyly of Opisthorchis viverrini populations in the lower Mekong basin, using mitochondrial DNA nad1 gene as the marker. Parasitol Int 59: 242-247. 